\title{
Gaming for Healthcare: A Bibliometric Analysis in Business and Management
}

\author{
Filomena Izzo $^{1}$, Ida Camminatiello ${ }^{2}$ \\ ${ }^{1}$ Assistant Professor in Management, Economics Department, Università degli Studi della Campania "Luigi \\ Vanvitelli", Capua (CE), Italy. \\ ${ }^{2}$ Assistant Professor in Statistics, Economics Department, Università degli Studi della Campania "Luigi \\ Vanvitelli”, Capua (CE), Italy \\ Correspondence: Filomena Izzo, Economics Department, Università degli Studi della Campania "Luigi \\ Vanvitelli”, Corso Gran priorato di Malta, 1, 81043 Capua (CE), Italy.
}

Received: October 21, 2020

Accepted: November 17, 2020

Online Published: November 24, 2020

doi:10.5539/ibr.v13n12p27

URL: https://doi.org/10.5539/ibr.v13n12p27

\begin{abstract}
The purpose of this paper is to scrutinize and classify the literature linking gaming for healthcare and management phenomena.

An objective bibliometric analysis is conducted, supported by subjective assessments based on studies focused on the linking of gaming for healthcare and management fields.

From the analysis and its evaluation, three clusters depicting literature linking gaming for healthcare and management phenomena are showed: management and governance public/private healthcare system; gaming and knowledge/strategic management; management health/medical insurance system using game theory. Moreover, the study shows the limits of existing literature on this topic and proposes future research topics.

This is one of the first attempts to comprehend the research stream which, over time, has paved the way to the intersection between gaming for healthcare and management fields.
\end{abstract}

Keywords: bibliometric analysis, gaming, game, healthcare, digital therapies, business and management

\section{Introduction}

In the healthcare field, digital therapies are the new frontier. These are apps and videogames, using for example Nintendo Wii or Microsoft Kinect, that not only support the patient in physical and psychological rehabilitation but treat him. The goal of digital therapies is to cure some diseases by playing.

Gamification refers to a process of enhancing a service with affordances for gameful experiences to support users' overall value creation (Huotari, Hamari, 2017). The application of gamification logic (puzzle-solving, the passage of levels, competition, and its reward) in the production of services by the non-play is used for years in many different fields, from management training to school education (Vervoort, 2019). The driver of digital therapy is patient innovation. Patient innovation is product-service solution designed by patients and their caregivers (Maffei et al., 2017; Olivera et al. 2015; Zejnilovic et al. 2016).

Gaming has the potential to revolutionize healthcare service. The game is a service system (Huotari, Hamari, 2017). According to Vargo et al. (2008, p. 145), a service system refers to "an arrangement of resources (including people, technology, information, etc.) connected to other systems by value propositions".

Some examples of game applications in the healthcare sector are the following. SuperPoteri videogame, used in dentistry for children, was designed to prevent fear from affecting a correct operation and to ensure that the prescribed therapy is put into practice carefully at home. Tommi videogame helps small oncology patients to positively face their path of care. Akili videogame aimed at treating attention deficit hyperactivity disorder, depressive disorder, autism spectrum disorders, and even multiple sclerosis. Ms-Fit videogame allows multiple sclerosis patients to perform movements to improve posture, balance, and breathing. Vitamin videogame is useful for physical rehabilitation. MirrorAble videogame is utilized for rehabilitation for children with stroke.

The pharmaceutical sector has just been touched by the digital transformation until a few years ago it was a closed system, difficult to be attacked by start-ups due to the strict regulations and the length of development 
projects (10-15 years for the approval of a drug).

Referring to gamification for the healthcare sector, a recent study, by Research Reports, shows that by 2022 the gamification business in health care will grow by as much as 55\%, get to USD 3,780 million. It is the beginning of a new era, with fewer drugs and more high-tech but more "natural" methods.

It is evident that gaming for healthcare is a new and interesting market, but there are no academic studies in business and management fields which analyze the phenomenon as a whole. To this, an objective bibliometric analysis is conducted and supported by subjective assessments, based on the previous and current studies on the intertwining of gaming for healthcare in business and management fields.

The paper proceeds as follows. The next section presents the methodology. Then, the results of the bibliometric analysis are showed. Finally, discussion, conclusions, and future research directions are provided.

\section{Methodology}

The research consists of five stages: study design; data collection; data analysis; data visualization and interpretation.

In the study design, we define the main objective of this research that is to analyse and systematize the various aspects of extant literature that lies at the intersection between gaming for healthcare and business and management realms. We adopt an objective and a subjective approach to examine how the topic of gaming and healthcare has been integrated into the business and management field.

For data collection, we select the Web of Science (WoS) database. Data analysis is performed by a bibliometric analysis which represents the objective approach. Bibliometrics refers to "the collection, the handling and the analysis of quantitative bibliographic data, derived from scientific publications" (Verbeek et al., 2002: 181). It consists of general descriptive statistics (e.g. identifying the main authors, publishing journals, etc) (Wu and Wu, 2017) and more sophisticated methods like the document co-citation, collaboration, and co-occurrence analyses (Briner and Denyer, 2012; Rosseau, 2012).

The bibliometric analysis is carried out by using the R package bibliometrix version 2.2.1 (Aria \& Cuccurullo, 2017) which also allows for extracting bibliometric networks using different units of analysis, i.e. citations, authors, countries, keywords, etc. It performs co-word analysis (Callon et al., 1983) by multiple correspondence analysis (Lebart et al., 1984) and hierarchical agglomerative clustering (Rousseeuw, 1987).

Bibliometrics can make a systematic, transparent, and reproducible review process based on the statistical measurement of science, scientists, or scientific activity (Broadus, 1987; Diodato, 1994; Pritchard, 1969; Crane, 1972).

Data visualization is used to represent a science map and the result of data analysis.

The last stage is interpretation, where the objective approach is integrated by a

subjective approach (qualitative analysis), which is based on scholars' interpretation of a given field of research. In fact, a qualitative assessment completes the bibliometric analysis, in particular, the literature linking gaming for healthcare in business and management phenomena is scrutinized and classified.

\section{Results of the Bibliometric Analysis}

We began by querying the Web of Science (WoS) database with the search term gaming in the topic - i.e. title, abstract and keywords - associated with, at least, one of the following terms: healthcare, health-care or health care in the topic. We selected the WoS Categories: business and management. This procedure yielded 69 documents extracted by 47 sources (Table 1.). Then we carried out the bibliometric analysis, by using the $\mathrm{R}$ package bibliometrix version 2.2.1 (Aria \& Cuccurullo, 2017). Such analysis opens by presenting the main information about data (Table 1.).

Leaving out the rows whose meaning is obvious, in the third row of Table 1 we find the number of keywords associated with the documents by WoS database (ID=263), then the number of keywords associated with the documents by the authors $(\mathrm{DE}=249)$. 
Table 1. Main Information about data

\begin{tabular}{ll} 
Documents & 69 \\
Sources (Journals, Books, etc.) & 47 \\
Keywords Plus (ID) & 263 \\
Author's Keywords (DE) & 249 \\
Period & $1991-17 / 10 / 2019$ \\
Average citations per documents & 9.812 \\
Authors & 173 \\
Author Appearances & 177 \\
Authors of single-authored documents & 13 \\
Authors of multi-authored documents & 160 \\
Single-authored documents & 13 \\
Documents per Author & 0.399 \\
Authors per Document & 2.51 \\
Co-Authors per Documents & 2.57 \\
Collaboration Index & 2.86 \\
\hline
\end{tabular}

In the sixth row of Table 1., there are the average citations per documents (9.812) calculated by the ratio between the total citations and the number of documents. In the twelfth row, the number of documents per author $(0.399)$ is calculated by dividing the number of documents and the number of authors, contrary the number of authors per document (2.51) is the ratio between the number of authors and the number of documents. The last two data denote a few documents e many authors. Finally, the number of Co-Authors per documents (2.57) is equal to the ratio between the Author Appearances and the documents and the collaboration index (2.86) is obtained by dividing the number of authors of multi-authored documents and the multi-authored documents. These two indices indicate a strong collaboration among the authors

Table 2. describes the document types: articles are the most part of the documents, revealing high-quality publications.

Table 2. Document types

\begin{tabular}{lc}
\hline Article & 48 \\
Article, Proceedings Paper & 2 \\
Book Review & 1 \\
Editorial Material & 1 \\
Proceedings Paper & 16 \\
Review & 1 \\
\hline
\end{tabular}

The scientific production, started in 1991, increased in the last years, except for 2015, highlighting the recent interest in the topic (Figure 1.). The number of articles for 2019 is incomplete due to the fact that the data collection ended on 17/10/2019. The annual percentage growth rate is equal to 9.372 , so it is in rapid growth. 


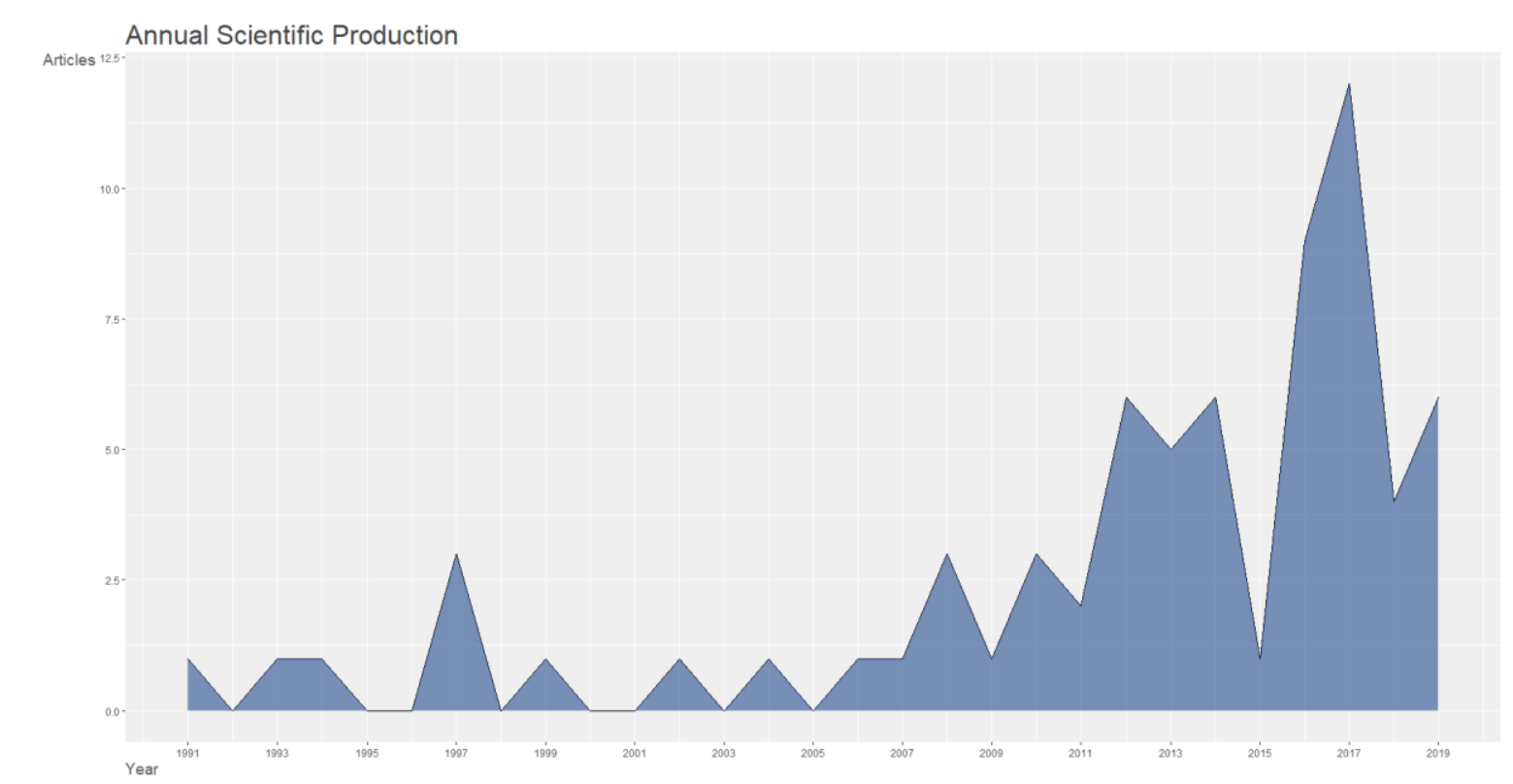

Year 199119931994199719992002200420062007200820092010201120122013201420152016201720182019

\begin{tabular}{llllllllllllllllllllll} 
Articles & 1 & 1 & 1 & 3 & 1 & 1 & 1 & 1 & 1 & 3 & 1 & 3 & 2 & 6 & 5 & 6 & 1 & 9 & 12 & 4 & 6 \\
\hline
\end{tabular}

Figure 1. Annual Scientific Production

Table 3. and Figure 2. report and represent the absolute (Articles) and relative (Freq) frequency distribution of affiliation countries, the Intra-country (SCP) and intercountry (MCP) collaboration number and intercountry collaboration index (MCP_Ratio).

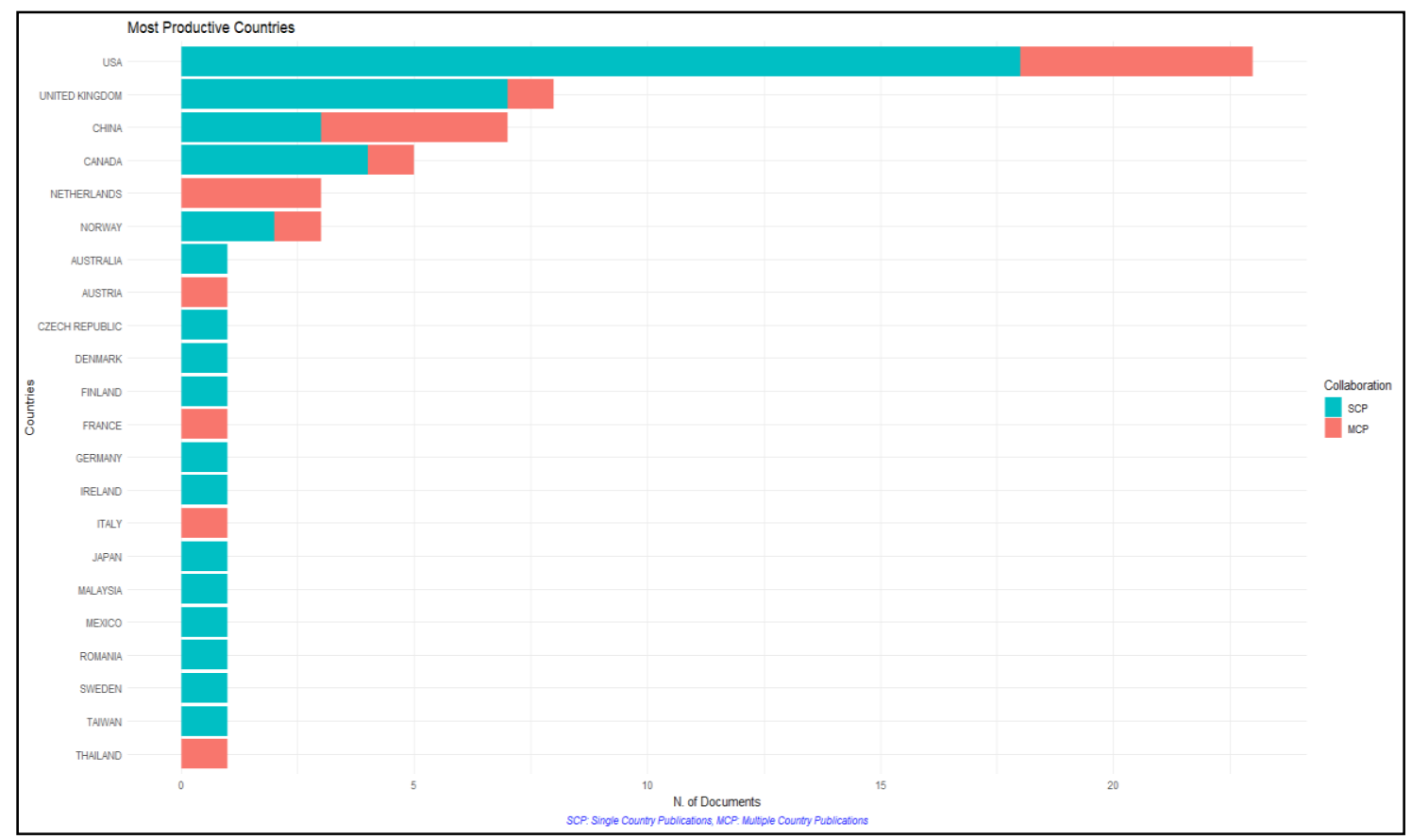

Figure 2. Corresponding Author's Countries 
Table 3. Corresponding Author's Countries

\begin{tabular}{lllllll}
\hline & Country & Articles & Freq & SCP & MCP & MCP_Ratio \\
\hline 1 & Usa & 23 & 0.3538 & 18 & 5 & 0.217 \\
2 & United Kingdom & 8 & 0.1231 & 7 & 1 & 0.125 \\
3 & China & 7 & 0.1077 & 3 & 4 & 0.571 \\
4 & Canada & 5 & 0.0769 & 4 & 1 & 0.2 \\
5 & Netherlands & 3 & 0.0462 & 0 & 3 & 1 \\
6 & Norway & 3 & 0.0462 & 2 & 1 & 0.333 \\
7 & Australia & 1 & 0.0154 & 1 & 0 & 0 \\
8 & Austria & 1 & 0.0154 & 0 & 1 & 1 \\
9 & Czech Republic & 1 & 0.0154 & 1 & 0 & 0 \\
10 & Denmark & 1 & 0.0154 & 1 & 0 & 0 \\
11 & Finland & 1 & 0.0154 & 1 & 0 & 0 \\
12 & France & 1 & 0.0154 & 0 & 1 & 1 \\
13 & Germany & 1 & 0.0154 & 1 & 0 & 0 \\
14 & Ireland & 1 & 0.0154 & 1 & 0 & 0 \\
15 & Italy & 1 & 0.0154 & 0 & 1 & 1 \\
16 & Japan & 1 & 0.0154 & 1 & 0 & 0 \\
17 & Malaysia & 1 & 0.0154 & 1 & 0 & 0 \\
18 & Mexico & 1 & 0.0154 & 1 & 0 & 0 \\
19 & Romania & 1 & 0.0154 & 1 & 0 & 0 \\
20 & Sweden & 1 & 0.0154 & 1 & 0 & 0 \\
21 & Taiwan & 1 & 0.0154 & 1 & 0 & 0 \\
22 & Thailand & 1 & 0.0154 & 0 & 1 & 1 \\
\hline
\end{tabular}

The USA claims the biggest number of documents and Intra-country (SCP) and intercountry (MCP) collaboration. USA, United Kingdom, China, Canada and Norway produce Intra-country (SCP) and intercountry (MCP) collaborations. Netherlands, Austria, France, Italy and Thailand present only intercountry collaborations. The remaining countries show only Intra-country collaborations.

The collaboration links between countries are displayed in Figure 3. The most productive countries - such as the USA, United Kingdom, China, Canada, Netherlands and Norway - are the most collaborative ones.

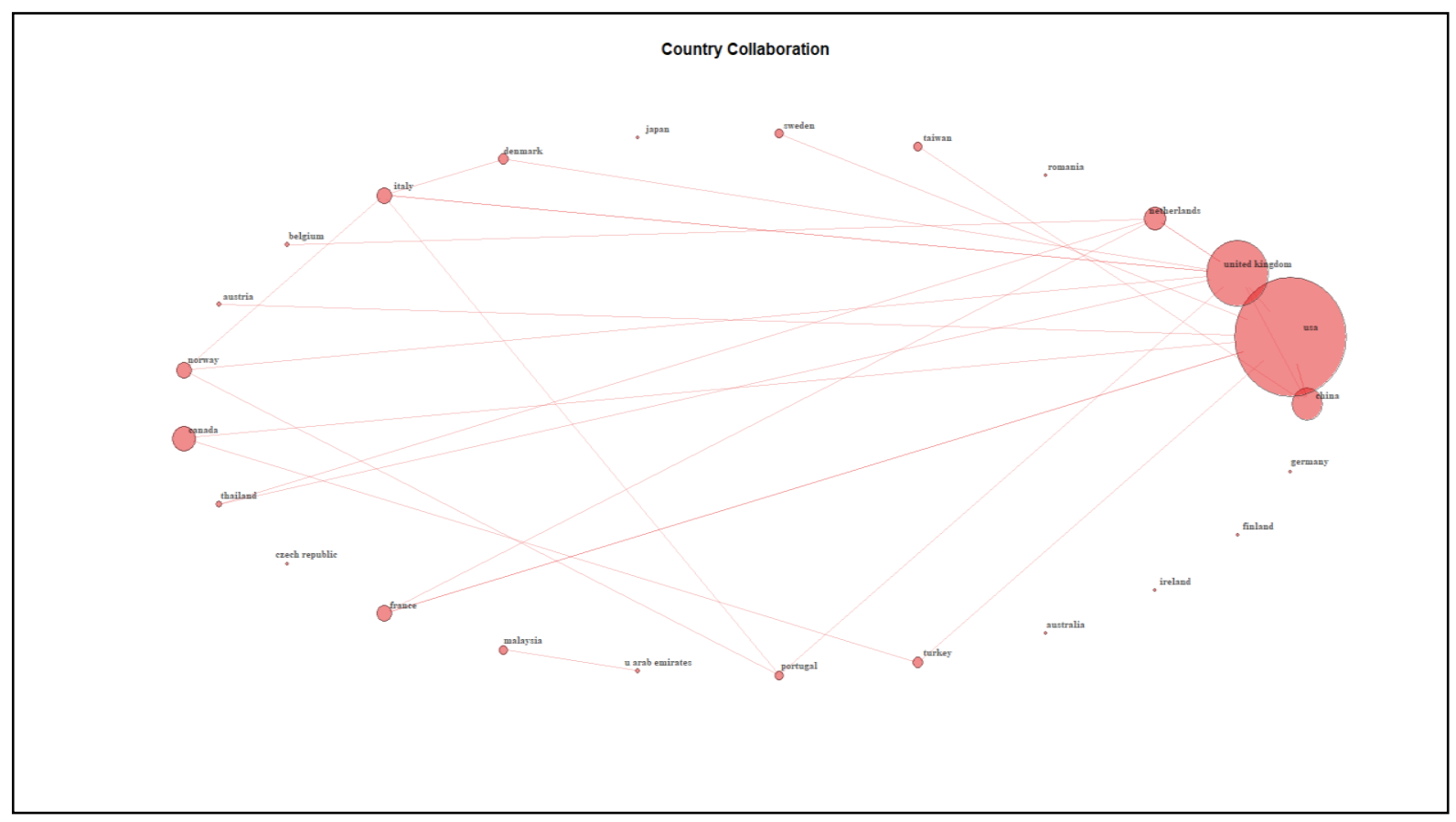

Figure 3. Country Collaboration 
Table 4. illustrates the total citations and the average article citations obtained by the ratio between the total citations and the number of articles. It is interesting to note that the USA shows the biggest number of total citations whereas Germany presents the highest average article citations. This is due to the fact that the USA is the most productive country, while Germany produced one of the most cited papers.

For sake of simplicity, we summarize the main results of the bibliometric analysis in several tables, such as most productive authors (Table 5.), top manuscripts per number of citations (Table 6.), most relevant sources (Table 7.) and most relevant keywords (Table 8.).

Table 5. shows the three authors who produced more than one publication and the number of articles they authored or co-authored. All the authors, but three, published only one article, thus reflecting that very few business and management scholars focused on the importance of gaming for healthcare.

Table 6. illustrates the top ten manuscripts per citations, the number of times each manuscript has been cited (TC) and the yearly average number of times each manuscript has been cited (TCperYear). These are highly cited papers given that their citations far exceed the average citations per documents which is equal to 9.812

The topic gaming in healthcare has been published by 47 sources, of which only 9 present more than one document, relieving that very few sources are specialized at dealing with the topic (Table 7.).

Table 8. presents the Authors' Keywords (DE) and the Keywords associated with the document by WoS database (ID) which occur more than once. The results tell us that the most frequent author Keywords (DE) in the data are "game theory," "healthcare" and "healthcare management"; whereas the most frequent keyword-plus (ID) is "model" closely followed by "quality", "care" and "health care".

After descriptive analysis, we can try to extract bibliometric networks using different units of analysis, i.e. citations, authors, countries, keywords, etc. All networks can be graphically visualized or modelled like as in Figure 3. which represents the country scientific collaboration.

Figure 4. displays the keyword plus co-occurrence network composed of nodes (keywords), connected by ties (co-occurrences). In the plot, nodes with higher degrees have larger balls. Looking at this graph, it seems clear that the main thematic nexus in the network is composed of "quality and model" combined with "healthcare and demand." These findings will be confirmed by cluster analysis.

Table 4. Citations per Country

\begin{tabular}{llll}
\hline & Country & Total Citations & Average Article Citations \\
\hline 1 & USA & 318 & 13.83 \\
2 & Canada & 77 & 15.40 \\
3 & United Kingdom & 73 & 9.12 \\
4 & China & 46 & 6.57 \\
5 & Germany & 27 & 27.00 \\
6 & Norway & 20 & 6.67 \\
7 & Ireland & 19 & 19.00 \\
8 & Denmark & 14 & 14.00 \\
9 & France & 12 & 12.00 \\
10 & Netherlands & 10 & 3.33 \\
11 & Italy & 4 & 4.00 \\
12 & Mexico & 4 & 4.00 \\
13 & Austria & 2 & 2.00 \\
14 & Taiwan & 2 & 2.00 \\
15 & Australia & 1 & 1.00 \\
16 & Finland & 1 & 1.00 \\
17 & Sweden & 1 & 1.00 \\
18 & Thailand & 1 & 1.00 \\
19 & Czech Republic & 0 & 0.00 \\
20 & Japan & 0 & 0.00 \\
21 & Malaysia & 0 & 0.00 \\
22 & Romania & 0 & 0.00 \\
\hline
\end{tabular}


Table 5. Most Productive Authors

\begin{tabular}{lll}
\hline & Authors & Articles \\
\hline 1 & Tang Cs & 3 \\
2 & Nagurney A & 2 \\
3 & Tayur S & 2 \\
\hline
\end{tabular}

Table 6. Top manuscripts per citations

\begin{tabular}{llll}
\hline & Paper & TC & TCperYear \\
\hline 1 & Anand Ks, 2011, Manage Sci & 72 & 9.00 \\
2 & Morrell K, 2008, J Manage Stud & 52 & 4.73 \\
3 & Nichols Na, 1994, Harv Bus Rev & 45 & 1.80 \\
4 & Cho Sh, 2013, MII\&Som-Manuf Serv Oper Manag & 38 & 6.33 \\
5 & Galor E, 1997, J Econ Manage Strategy & 35 & 1.59 \\
6 & Bradshaw-Camball P, 1991, Organ Sci & 31 & 1.11 \\
7 & Xu F, 2017, Tourism Manage & 28 & 14.00 \\
8 & Hu Qj, 2012, MII\&Som-Manuf Serv Oper Manag & 27 & 3.86 \\
9 & Bode I, 2006, Public Manag Rev & 27 & 2.08 \\
10 & Grennan M, 2014, Manage Sci & 26 & 5.20 \\
\hline
\end{tabular}

Table 7. Most Relevant Sources

\begin{tabular}{|c|c|c|}
\hline & Sources & Articles \\
\hline 1 & Management Science & 7 \\
\hline 2 & Journal Of Economics $\ \ \&$ Management Strategy & 5 \\
\hline 3 & European Journal Of Operational Research & 4 \\
\hline 4 & M $\ \&$ Som-Manufacturing $\| \&$ Service Operations Management & 4 \\
\hline 5 & Public Management Review & 3 \\
\hline 6 & Information Systems Research & 2 \\
\hline 7 & Organization Studies & 2 \\
\hline 8 & Proceeding Of Knowledge Management International Conference (Kmice) 2014 Vols 1 and 2 & 2 \\
\hline 9 & Tourism Management & 2 \\
\hline
\end{tabular}

Table 8. Most Relevant Keywords

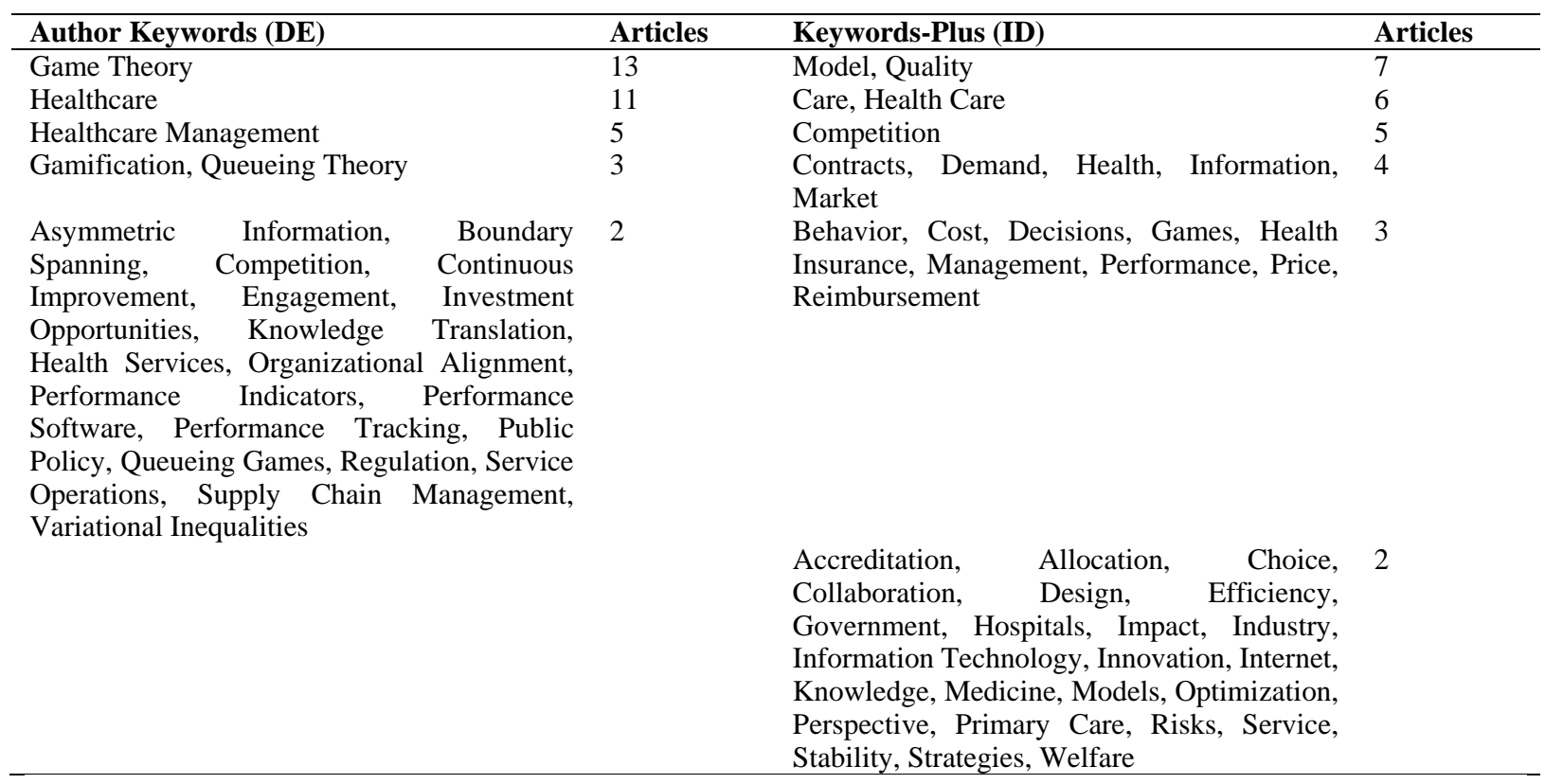




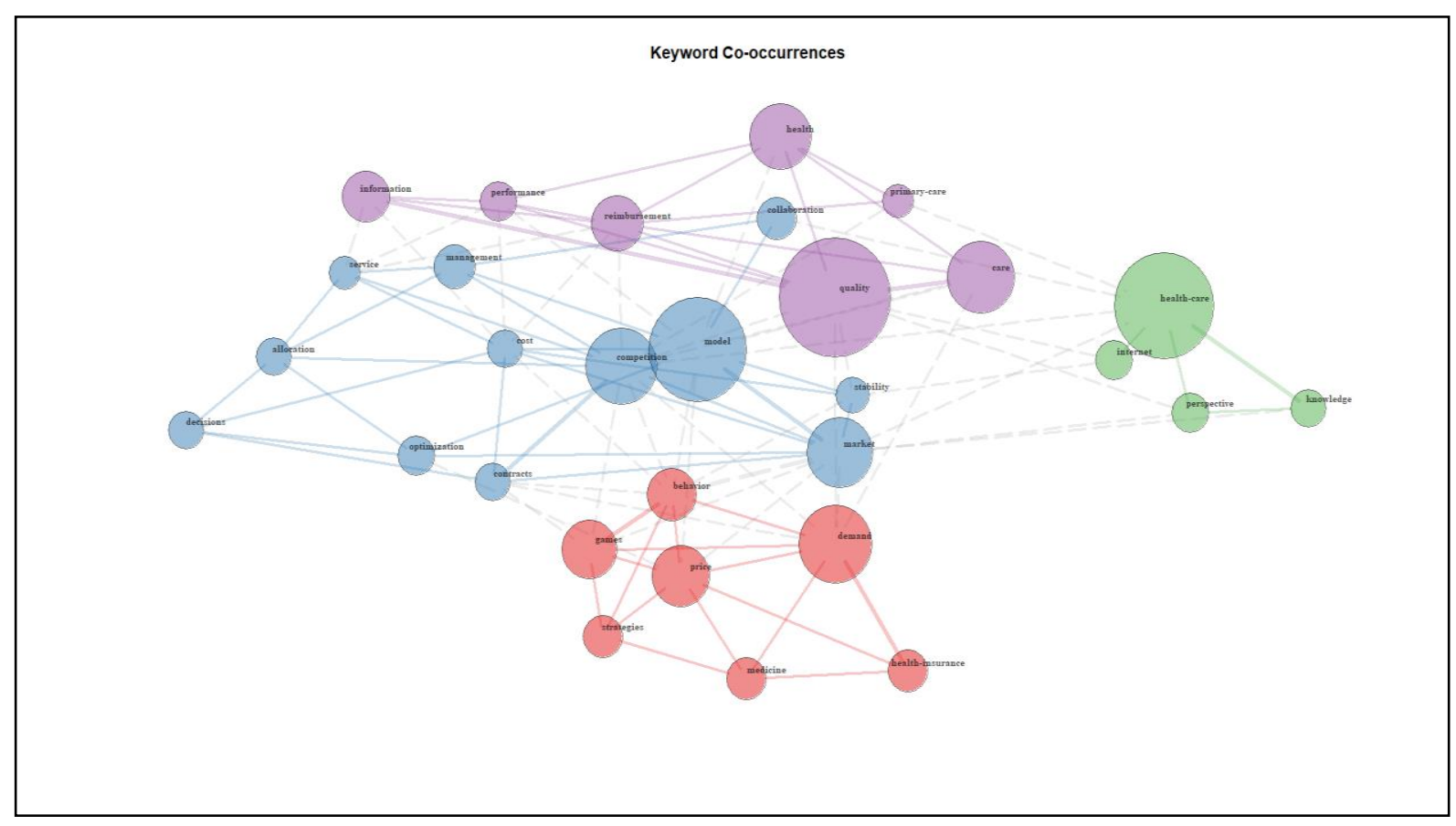

Figure 4. Keyword co-occurrence plot

Finally, we perform co-word analysis (Callon et al., 1983) by multiple correspondence analysis (MCA) and hierarchical agglomerative clustering (HAC). The statistic units are the documents and the variables are the terms extracted from titles. The MCA allows us to produce a semantic map of the research field. The HAC seeks to build a hierarchy of clusters.

The HAC leads to the dendrogram of Figure 5. which suggests of yielding three clusters. To validate this suggestion we execute silhouette analysis which provides a graphical representation of how well each object has been classified. Three clusters present: higher average silhouette width than 4 and 5 clusters; none observation assigned to the wrong cluster and very few borderline observations. Therefore three clusters are the optimal choice. The silhouette plot (Figure 6) shows the cluster size.

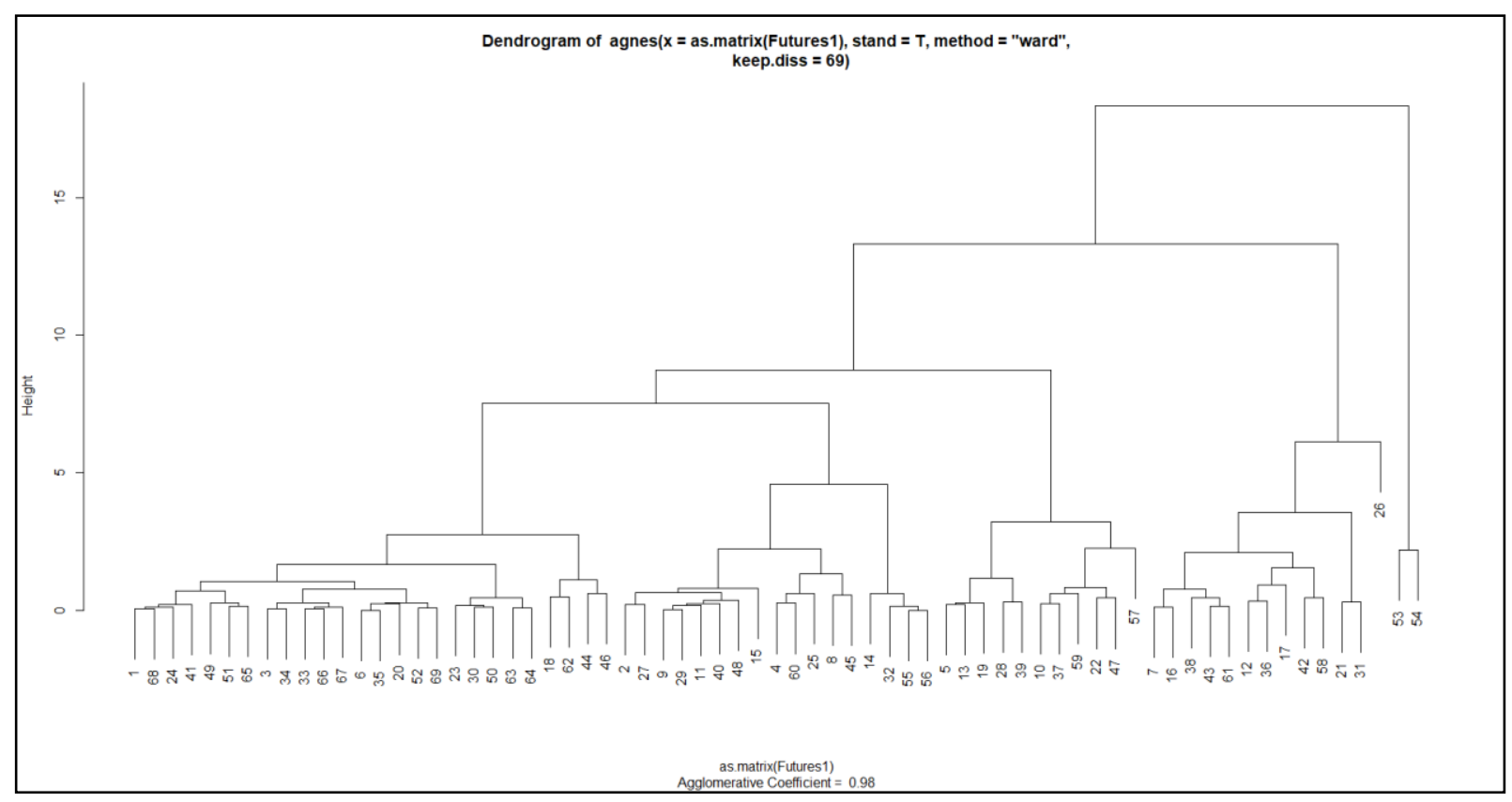

Figure 5. Dendrogram of the documents 


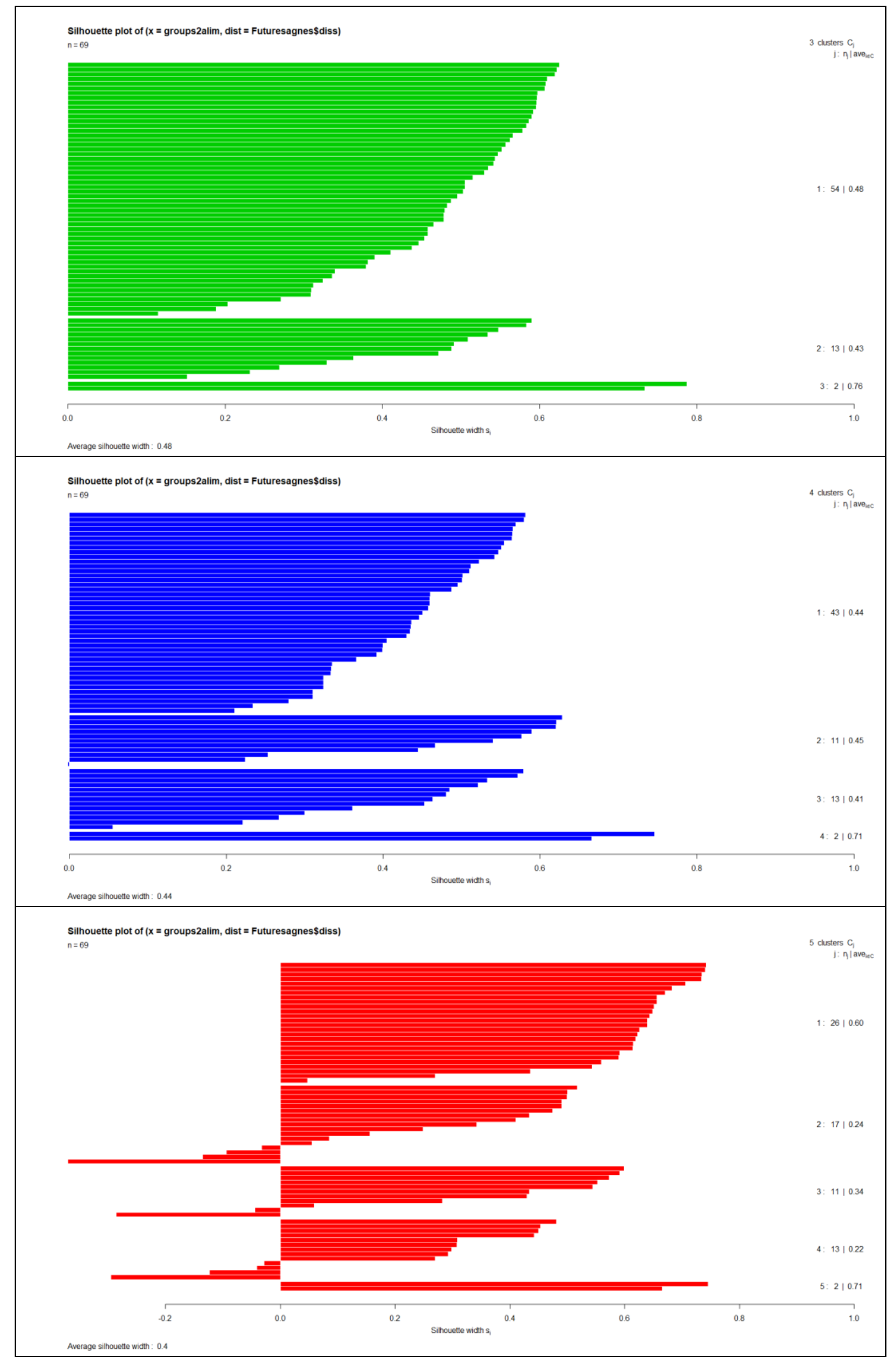

Figure 6. Silhouette plot 
Table 10 illustrates the cluster results. In the second column of table 10 there are the documents, then we have the total citations (TC), the cluster to which each document belongs (cluster) as well as its neighbour cluster (fourth column) and the silhouette width (sil_width) of the observation. Green rows indicate the observations which well matched to the assigned cluster, contrary, red rows specify the very few borderline observations.

Table 10. Cluster results

\begin{tabular}{|c|c|c|c|c|c|}
\hline $\mathbf{N}$ & Paper & TC & Cluster & $\begin{array}{c}\text { cluster } \\
\text { neighbord }\end{array}$ & sil_width \\
\hline 1 & anand ks, 2011, manage sci & 72 & 1 & 2 & 0.4580531 \\
\hline 2 & morrell k, 2008, j manage stud & 52 & 1 & 2 & 0.6251249 \\
\hline 3 & nichols na, 1994, harv bus rev & 45 & 1 & 2 & 0.5919003 \\
\hline 4 & cho sh, 2013, mIl\&som-manuf serv oper manag & 38 & 1 & 2 & 0.6098455 \\
\hline 5 & galor e, $1997, \mathrm{j}$ econ manage strategy & 35 & 1 & 2 & 0.5025678 \\
\hline 6 & bradshaw-camball p, 1991, organ sci & 31 & 1 & 2 & 0.5049784 \\
\hline 7 & $\mathrm{xu} f, 2017$, tourism manage & 28 & 2 & 1 & 0.4713434 \\
\hline 8 & hu qj, 2012, mIl\&som-manuf serv oper manag & 27 & 1 & 2 & 0.5146393 \\
\hline 9 & bode i, 2006, public manag rev & 27 & 1 & 2 & 0.6077247 \\
\hline 10 & grennan $\mathrm{m}, 2014$, manage sci & 26 & 1 & 2 & 0.3789382 \\
\hline 11 & tian $\mathrm{k}, 2014, \mathrm{j}$ consum res & 21 & 1 & 2 & 0.5957468 \\
\hline 12 & $\begin{array}{l}\text { coyle d, 2009, chi2009: proceedings of the } 27 \text { th annual chi conference on } \\
\text { human factors in computing systems, vols } 1-4\end{array}$ & 19 & 2 & 1 & 0.4876606 \\
\hline 13 & lu ms, $1999, \mathrm{j}$ econ manage strategy & 17 & 1 & 2 & 0.5294229 \\
\hline 14 & nagurney a, 2013, int trans oper res & 16 & 1 & 2 & 0.4652841 \\
\hline 15 & hu qj, 2014, mark sci & 15 & 1 & 2 & 0.5568527 \\
\hline 16 & baril c, 2016, eur j oper res & 15 & 2 & 1 & 0.4911737 \\
\hline 17 & wu j, 2016, inf manage & 14 & 2 & 1 & 0.1515707 \\
\hline 18 & knudsen $\mathrm{m}, 2011$, organ stud & 14 & 1 & 2 & 0.3091836 \\
\hline 19 & brekke $\mathrm{kr}, 2012$, j econ manage strategy & 14 & 1 & 2 & 0.5415809 \\
\hline 20 & mamani h, 2013, manage sci & 13 & 1 & 2 & 0.5433639 \\
\hline 21 & andritsos da, 2014, eur j oper res & 12 & 2 & 1 & 0.5474981 \\
\hline 22 & zhang dj, 2016, manage sci & 11 & 1 & 2 & 0.4458215 \\
\hline 23 & lander b, 2016, res policy & 11 & 1 & 2 & 0.3357857 \\
\hline 24 & knight va, 2013, eur j oper res & 11 & 1 & 2 & 0.4536934 \\
\hline 25 & lu sf, 2013, manage sci & 9 & 1 & 2 & 0.5833323 \\
\hline 26 & hammedi $\mathrm{w}, 2017$, j serv manage & 7 & 2 & 1 & 0.3631486 \\
\hline 27 & ata b, 2017, manage sci & 7 & 1 & 2 & 0.6220851 \\
\hline 28 & skountridaki 1, 2017, tourism manage & 7 & 1 & 2 & 0.3816189 \\
\hline 29 & $\begin{array}{l}\text { sahinoglu } \mathrm{m}, 2012 \text {, international conference on asia pacific business } \\
\text { innovation and technology management }\end{array}$ & 6 & 1 & 2 & 0.6065113 \\
\hline 30 & demirezen em, 2016, inf syst res & 6 & 1 & 2 & 0.3398193 \\
\hline 31 & simeone $1,2017, \mathrm{j}$ knowl manag & 4 & 2 & 1 & 0.5339975 \\
\hline 32 & stith ss, 2016, j econ manage strategy & 4 & 1 & 2 & 0.4874284 \\
\hline 33 & karanfil o, 2008, oper res & 4 & 1 & 2 & 0.5969615 \\
\hline 34 & dai t, 2017, mII\&som-manuf serv oper manag & 4 & 1 & 2 & 0.5972559 \\
\hline 35 & trinkaus $\mathrm{j}, 2002, \mathrm{j}$ bus ethics & 4 & 1 & 2 & 0.5049784 \\
\hline 36 & d'silva j, 2012, technol anal strateg manage & 3 & 2 & 1 & 0.5090647 \\
\hline 37 & zhou w, 2017, eur j oper res & 3 & 1 & 2 & 0.4107217 \\
\hline 38 & merschbrock c, 2016, facilities & 3 & 2 & 1 & 0.3292313 \\
\hline 39 & gauteplass aa, 2017, prop manag & 3 & 1 & 2 & 0.3123196 \\
\hline 40 & ma ca, $1993, \mathrm{j}$ econ manage strategy & 3 & 1 & 2 & 0.6195781 \\
\hline 41 & froelich ka, 2012, nonprofit manag leadersh & 3 & 1 & 2 & 0.4955205 \\
\hline 42 & kislov r, 2017, organ stud & 2 & 2 & 1 & 0.5831716 \\
\hline
\end{tabular}


lin $\mathrm{mh}, 2012$, picmet '12: proceedings - technology management for

43 emerging technologies

44 koinig i, 2017, int j advert

45 knight $\mathrm{v}, 2017$, j oper res soc

46 guo p, 2019, mll\&som-manuf serv oper manag

47 zhang h, 2018, serv sci

lawrence e, 2010, 23rd bled econference etrust: implications for the

48 individual, enterprises and society

49 bjorkman a, 2018, internet res

50 buske k, 2016, adm sci

51 laikari a, 2008, vtt symposium on service science, technology and business

52 nagurney a, 2019, omega-int j manage sci

chen zhichu cz, 2015, proceedings of 2014 china international conference on

53 insurance and risk management

54 sugawara s, 2017, comput econ

fink t, 1997, aqp's 19th annual spring conference and resource mart, 1997

55 proceedings - " the spirit of working together

56 korfhage de, 1997, asqc's 51st annual quality congress proceedings

57 cernik o, 2016, contributions to game theory and management, vol ix

feng w, 2018, proceedings of 2018 china marketing international conference:

58 smart marketing: human, technology and innovation

cheng yu cy, 2007, proceedings of the 2007 international conference on

59 management science and engineering, finance analysis section

60 douglas s, 2019, public manag rev

zahari nm, 2014, proceeding of knowledge management international

61 conference (kmice) 2014, vols 1 and 2

enakimio i, 2010, proceedings of the 11th european conference on

62 knowledge management, vols 1 and 2

alkadi i, 2004, service systems and service management - proceedings of

63 icsssm `04, vols 1 and 2

64 hammond j, 2019, public manag rev

65 savva n, 2019, manage sci

66 dollinger $\mathrm{m}, 2010$, bus horiz

67 bouayad 1, 2019, inf syst res

chohan fm, 2014, proceeding of knowledge management international

68 conference (kmice) 2014, vols 1 and 2

69 khatib m, 2018, performance management or management performance?

\begin{tabular}{|c|c|c|c|}
\hline 2 & 2 & 1 & 0.2317147 \\
\hline 2 & 1 & 2 & 0.4794688 \\
\hline 1 & 1 & 2 & 0.5516326 \\
\hline 1 & 1 & 2 & 0.3901045 \\
\hline 1 & 1 & 2 & 0.4576514 \\
\hline 1 & 1 & 2 & 0.5861733 \\
\hline 1 & 1 & 2 & 0.4825709 \\
\hline 1 & 1 & 2 & 0.2708560 \\
\hline 1 & 1 & 2 & 0.5620074 \\
\hline 1 & 1 & 2 & 0.5656700 \\
\hline 0 & 3 & 1 & 0.7873572 \\
\hline 0 & 3 & 1 & 0.7336235 \\
\hline 0 & 1 & 2 & 0.4778288 \\
\hline 0 & 1 & 2 & 0.4778288 \\
\hline 0 & 1 & 2 & 0.2030554 \\
\hline 0 & 2 & 1 & 0.5898715 \\
\hline 0 & 1 & 2 & 0.3241610 \\
\hline 0 & 1 & 2 & 0.5961867 \\
\hline 0 & 2 & 1 & 0.2689221 \\
\hline 0 & 1 & 2 & 0.3098046 \\
\hline 0 & 1 & 2 & 0.1145598 \\
\hline 0 & 1 & 2 & 0.1886580 \\
\hline 0 & 1 & 2 & 0.5345560 \\
\hline 0 & 1 & 2 & 0.5901593 \\
\hline 0 & 1 & 2 & 0.5784810 \\
\hline 0 & 1 & 2 & 0.4374536 \\
\hline 0 & 1 & 2 & 0.5470630 \\
\hline
\end{tabular}

The results of MCA and HCA are plotted on the two-dimensional map of Figure 7. Looking at Figure 7., we observe that:

1. the first cluster is mainly characterised by the following terms: excellence, organization, measurement, performance, supplier, chain, provider, kidney, price, pharmaceutical, network, impact, unit, cost, dynamic, system, social, narrative, online, elderly, health, management, care, risk, communities, policies, time, improve.

2. The second cluster is mainly characterised by the following terms: mechanism, increase, user, healthcare, gamification, case, role, design, innovation, activities, service, patient, serious, knowledge, effect, development.

3. The third cluster is mainly characterised by the following terms: analysis, approach, barrier, cooperative, economics, empirical, facility, game, hazard, hospital, insurance, market, medical, model, separate, studies, theories, tourism. 


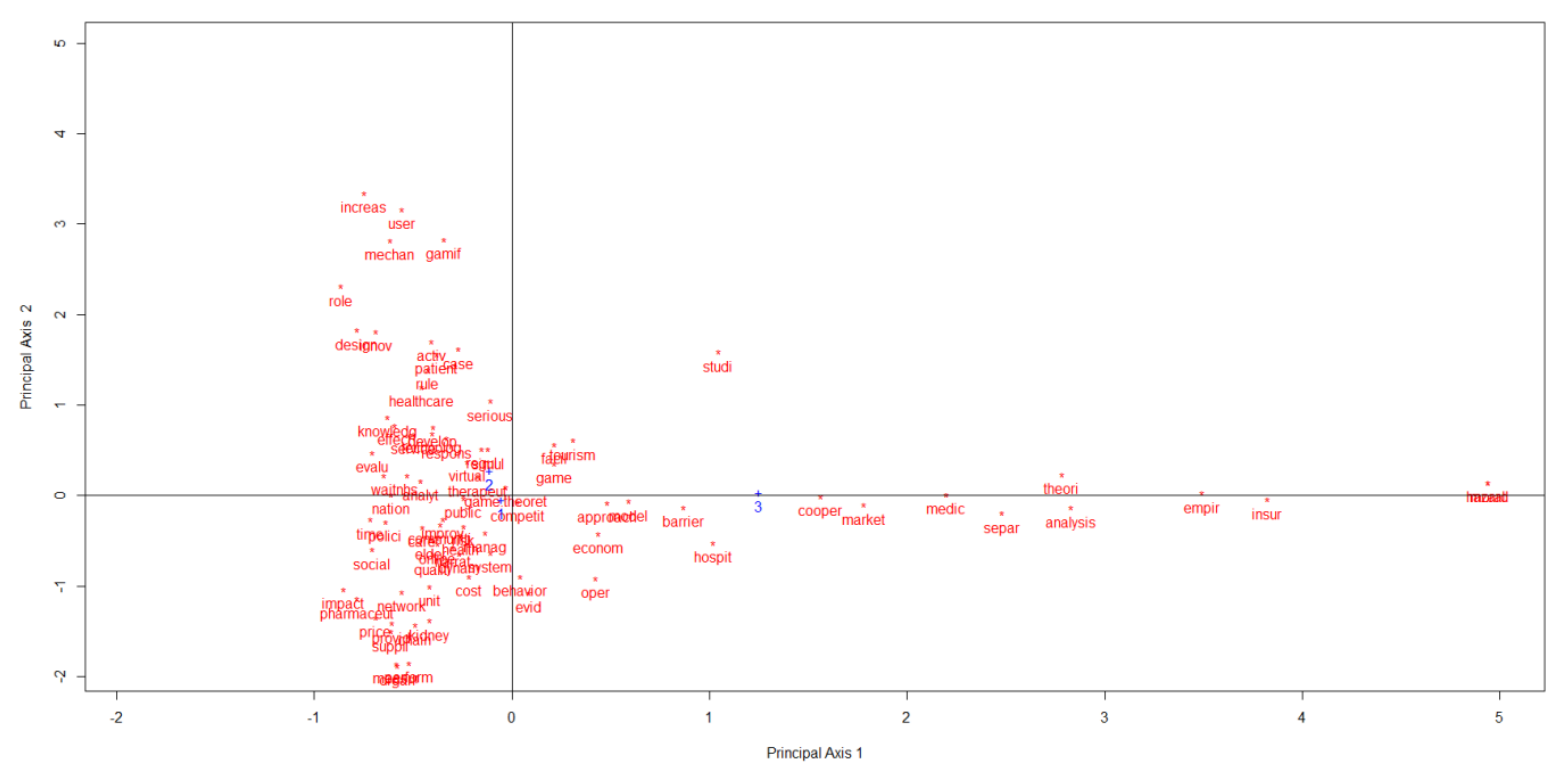

Figure 7. Two-dimensional map

We proceed with a qualitative analysis of the clusters, in particular, we proceed with the study of the titles, abstracts and keywords of the papers that fit better.

The first cluster is composed of 54 papers, whose 28 fit well. The qualitative analysis of these 28 papers shows that 23 focus on "management and governance public/private healthcare system with application of game theory" e 5 papers on "game technology for healthcare": Tian et al. (2014), Karanfil and Barlas (2008), Lawrence et al. (2010), Laikari (2008), Khatib (2018).

Tian et al. (2014) focus on the power of game technology-enhanced narratives to build collaborative therapeutic communities and to provide the impetus for affecting social change and action in health care systems.

Karanfil and Barlas (2008) concentrate on the power of game technology to develop alternative therapies for body water disorders.

Lawrence et al. (2010) present an analytic framework for investigating interactive gaming technologies in order to: improve the physical and mental health outcomes; help improve the quality of life of the elderly and the chronically unwell and inform whether they are living in their own homes or in aged care facilities.

Laikari (2008) shows gaming has a lot of potentials to provide various new service business opportunities for entertainment and recreation as well as for the healthcare sectors.

Khatib (2018) analyses the relation between computer games and risk behaviours.

The second cluster is made up of 13 articles, of which 5 fit good, these 5 papers focus on the topic "gaming and knowledge/strategic management"; belong in this group: Simeone et al. (2017), D'Silva et al (2012), Kislov et al. (2017).

Simeone et al. (2017) analyse the intersection of three different fields: open innovation, knowledge management and design (based on gaming principle) for innovation.

D'Silva et al (2012) describe how an innovation impasse in nanomedicine could have ensued if the traditional wait and watch strategies of legislators and regulators had been followed. They explain how waiting games were avoided through the opening up and distribution of regulatory approaches.

Kislov et al. (2017), drawing on a qualitative longitudinal case study of a collaborative partnership between a university and healthcare organizations, describe changes in the structure, sources and mutual convertibility of capital assets over time.

The third cluster is composed of 2 articles that fit very well: Chen and Ma (2015), Sugawara and Omori (2017). 
They are focused on the study of management health/medical insurance systems using game theory.

\section{Discussion}

The study points out the most part of the documents are papers, revealing high-quality publications. Moreover, the most productive countries are the USA with the biggest number of documents and Intra-country and inter-country collaboration.

All the authors, but three, published only one article, thus reflecting that there are few scholars (in business and management) focused on the study of gaming for healthcare. This data is also confirmed by the analysis of the number of sources; in fact, the topic "gaming for healthcare" has been published by 47 sources, of which only 9 present more than one document, relieving that very few sources are specialized at dealing with the topic.

Scientific production does not present a regular trend, but it is in rapid growth in the last years, highlighting the recent interest in the topic.

The analysis of the main keywords shows that the key topic of scientific production has been the "game theory". This data is confirmed by the cluster analysis which highlights the thematic "game theory" applied to the healthcare sector is the prevailing one. In fact, we only found 5 papers on "game technology for healthcare": Tian et al. (2014), Karanfil and Barlas (2008), Lawrence et al. (2010), Laikari (2008), Khatib (2018).

Among the top 10, there are 3 papers that do not fit well with the related clusters, they are: Anand et al. (2011), Xu et al. (2017), Grennan (2014).

Anand et al. (2011) analyse trade-offs quality-speed conundrum in customer-intensive services (healthcare sector) adopting queuing games theory.

$\mathrm{Xu}$ et al. (2017) studied gamification of tourism can contribute to more rewarding interactions, such as engaging tourists in experiential co-creation and training service providers for innovative processes and functions. Gamification can be used to enhance tourists on site experiences; in fact, location based games encourage on site engagement with the destination, augmented reality games interact the player with the real surrounding tourism attractions; gaming as an entertainment tool to kill time. As well, gamification increases brand awareness and loyalty to the destination; in fact, online games recall memories, encourage sharing experiences, inviting friends, advocate the destination, rewards/coupons in the game and gamified loyalty programs encourage repeat visits.

Grennan (2014) presents bargaining ability and competitive advantage in the medical devices market applying game theory.

In summary, the cluster analysis and the qualitative study show that the studies on the topic "gaming for healthcare" are recent and very few, in fact, only 5 articles out of 69 were found: Tian et al. (2014), Karanfil and Barlas (2008), Lawrence et al. (2010), Laikari (2008), Khatib (2018).

\section{Conclusion and Future Research}

In the healthcare industry, the new frontier is gaming therapy. In fact, recently there are more gaming technology applications in the healthcare market, but there are no academic studies in business and management fields which analyze the phenomenon as a whole. Starting from this gap in the literature, the present study is inserted. To this, the purpose of this paper was to scrutinize and classify the literature linking gaming for healthcare and management phenomena.

The paper offers a bibliometric analysis, supported by a qualitative approach, of the concept of gaming for healthcare, showing the different aspects of this concept mainly referring to the managerial literature.

From the analysis, three clusters emerged: the first one is on management and governance of public/private healthcare system; the second one is on gaming and knowledge/strategic management; the third is on the management of health/medical insurance system by using game theory.

The results highlight that there are very few articles on fundamental aspects for the success of digital therapies: the patient/player engagement; so that, future studies could contribute to the debate on this topic. Moreover, another not analyzed aspects in the literature are what characterizes patient innovation in healthcare concerning other forms of user innovation and the contemporary involvement of different communities: the scientific community (doctors and specialists), the patient community, the community of those who design and produce and finally the institutional system that rules all these subjects. What are the critical success factors of gaming for digital therapies? What are the strategies adopted by companies and/or healthcare communities to promote patient/player engagement for digital therapies? Will these new technologies contribute to making the co-creation of health services easier and more effective? There are no studies on these topics, future studies could contribute to the 
debate on these matters.

As with most studies, this research offers interesting insights, but it is also affected by some limitations. For instance, a multidisciplinary approach would request a different bunch of keywords such as multidisciplinary. Therefore, future research can be deeper and examine this scenario and enlarge the pool of papers. Alongside, there are other chances for a content analysis which could show other key aspects of the current research topic on gaming for healthcare.

\section{References}

Anand, K. S., Paç, M. F., \& Veeraraghavan, S. (2011). Quality-Speed Conundrum: Trade-offs in Customer-Intensive Services. Management Science, 57(1), 40-56. https://doi.org/10.1287/mnsc. 1100.1250

Aria, M., \& Cuccurullo, C. (2017). Bibliometrix: An R-tool for comprehensive science mapping analysis. Journal of Informetrics, 11(4), 959-975. https://doi.org/10.1016/j.joi.2017.08.007

Briner, R. B., \& Denyer, D. (2012). Systematic review and evidence synthesis as a practice and scholarship tool. In Handbook of evidence-based management: Companies, classrooms and research, 112-129. https://doi.org/10.1093/oxfordhb/9780199763986.013.0007

Broadus, R. (1987). Toward a definition of bibliometrics. Scientometrics, 12(5-6), 373-379. https://doi.org/10.1007/BF02016680

Callon, M., Courtial, J. P., Turner, W. A., \& Bauin, S. (1983). From translations to problematic networks: An introduction to co-word analysis. Social Science Information, 22(2), 191-235. https://doi.org/10.1177/053901883022002003

Chen, Z., \& Ma, Q. (2015). Study on the Degree of Moral Hazard in Our Medical Insurance -Based on Empirical Analysis Using Elasticity Theory. Proceedings of 2014 China International Conference On Insurance and Risk Management, 281-300.

Crane, D. (1972). Invisible colleges: Diffusion of knowledge in scientific communities. Chicago: University of Chicago Press.

Diodato, V. (1994). Dictionary of bibliometrics. Binghamton, NY: Haworth Press.

D'Silva, J. R., Douglas K. R., \& Shelley-Egan, C. (2012). A game with rules in the making - how the high probability of waiting games in nanomedicine is being mitigated through distributed regulation and responsible innovation. Technology Analysis \& Strategic Management, 24(6), 583-602. https://doi.org/10.1080/09537325.2012.693671

Grennan, M. (2014). Bargaining Ability and Competitive Advantage: Empirical Evidence from Medical Devices. Management Science, 60(12), 3011-3025. https://doi.org/10.1287/mnsc.2014.2006

Huotari, K., \& Hamari, J. (2017). A definition for gamification: anchoring gamification in the service marketing literature. Electron Markets, 27, 21-31. https://doi.org/10.1007/s12525-015-0212-z

Karanfil, O., \& Barlas, Y. (2008). A Dynamic Simulator for the Management of Disorders of the Body Water Homeostasis. Operations Research, 56(6), 1474-1492. https://doi.org/10.1287/opre.1080.0618

Khatib, M. (2018). Modern computer games and their risk to teenagers. Review of Management and Economic Engineering International Management Conference, 544-547.

Kislov, R., Hyde, P., \& McDonald, R. (2017). New Game, Old Rules? Mechanisms and Consequences of Legitimation in Boundary Spanning Activities. Organization Studies, 38(10), 1421-1444. https://doi.org/10.1177/0170840616679455

Laikari, A. (2008). Exergaming - combining real life and virtual communities to improve wellbeing. VTT Symposium on Service Science, Technology and Business, 253, 169-177.

Lawrence, E., Sax, C., \& Navarro, K. F. (2010). Improving Health Outcomes for the Elderly An Analytic Framework. In 23rd Bled eConference eTrust: Implications for the Individual, Enterprises and Society Proceedings, pp. 441-454.

Lebart, L., Morineau, A., \& Warwick, K. M. (1984). Multivariate descriptive statistical analysis (correspondence analysis and related techniques for large matrices). Chichester: Wiley.

Maffei, S., Bianchini, M., Parini, B., \& Delli, Z. E. (2017). MaketoCare. Un ecosistema di attori e soluzioni user-centered per l'innovazione nel campo dell'healthcare. Libraccio Editore. 
Oliveira, P., Zejnilovic, L., Canhao, H., \& von Hippel, E. (2015). Patient innovation under rare diseases and chronic needs. Orphanet Journal of Rare Diseases. https://doi.org/10.2139/ssrn.2456580

Pritchard, A. (1969). Statistical bibliography or bibliometrics. Journal of Documentation, 25, 348.

Rousseau, D. M. (Ed.) (2012). The Oxford handbook of evidence-based management. Oxford University Press. https://doi.org/10.1093/oxfordhb/9780199763986.001.0001

Rousseeuw, P. J. (1987). Silhouettes: A Graphical Aid to the Interpretation and Validation of Cluster Analysis. Journal of Computational and Applied Mathematics, 20, 53-65. https://doi.org/10.1016/0377-0427(87)90125-7

Simeone, L., Secundo, G., \& Schiuma, G. (2017). Knowledge translation mechanisms in open innovation: the role of design in R\\&D projects. Journal of Knowledge Management, 21(6), 1406-1429. https://doi.org/10.1108/JKM-10-2016-0432

Sugawara, S., \& Omori, Y. (2017). An Econometric Analysis of Insurance Markets with Separate Identification for Moral Hazard and Selection Problems. Computational Economics, 50(3), 473-502. https://doi.org/10.1007/s10614-016-9594-z

Tian, K., Sautter, P., Fisher, D., Fischbach, S., Luna-Nevarez, C., Boberg, K., ... Vann, R. (2014). Transforming Health Care: Empowering Therapeutic Communities through Technology-Enhanced Narratives. Journal of Consumer Research, 41(2), 237-260. https://doi.org/10.1086/676311

Vargo, S., \& Lusch, R. (2008). Service-dominant logic: Continuing the evolution. Journal of the Academy of Marketing Science, 36(1), 1-10. https://doi.org/10.1007/s11747-007-0069-6

Verbeek, A., Debackere, K., Luwel, M., \& Zimmermann, E. (2002). Measuring progress and evolution in science and technology - I: The multiple uses of bibliometric indicators. International Journal of management reviews, 4(2), 179-211. https://doi.org/10.1111/1468-2370.00083

Vervoort, J. M. (2019). New frontiers in futures games: leveraging game sector developments. Futures, 105, 174-186. https://doi.org/10.1016/j.futures.2018.10.005

Wu, Y. C. J., \& Wu, T. (2017). A decade of entrepreneurship education in the Asia Pacific for future directions in theory and practice. Management Decision, 55(7), 1333-1350. https://doi.org/10.1108/MD-05-2017-0518

Xu, F., Buhalis, D., \& Weber, J. (2017). Serious games and the gamification of tourism. Tourism Management, 60, 244-256. https://doi.org/10.1016/j.tourman.2016.11.020

Zejnilovic, L., Oliveira, P., \& Canhao, H. (2016). Innovations by and for the patients: and how can we integrate them into the future health care system. In Albach, H., Meffertt, H., Pinkwart, A., Reichwald, R., von Eiff, W. (Eds.), Boundaryless Hospital. Rethink and Redefine Health Care Management. Springer.

\section{Copyrights}

Copyright for this article is retained by the author(s), with first publication rights granted to the journal.

This is an open-access article distributed under the terms and conditions of the Creative Commons Attribution license (http://creativecommons.org/licenses/by/4.0/). 